\title{
Kotekan in the Traditional Shona Mbira Music of Zimbabwe
}

\author{
LEWISPETERMAN \\ Musicology and Ethnomusicology in the School of Music and Dance \\ at San Diego State University and the Center for World Music, USA
}

\begin{abstract}
This article documents musical interlocking as it is traditionally practiced among the Shona people of Zimbabwe. Its focus is on the music of the mbira dzavadzimu, a traditional musicial instrument that consists of 22-25 or more keys distributed over three manuals(keyboards) played with both thumbs and one index finger. Numerous musical examples,using notational symbols developed for this study, are used throughout to clarify all technicaldetails. Most of the notational symbols are the same or similar to those used by Paul Berliner in his classic study The Soul of Mbira (Berliner: 1978). Six complete traditional mbira dzavadzimu pieces are presented in easy-to-read notated form: "Nhemamusasa," “Chakwi," "Nhemamusasa Variation," "Nyamaropa," "Shumba,” and “Taireva.” Four different categories ofinterlocking procedures form the core of the article: 1) Interlocking in Solo Mbira Music; 2) Interlocking in Two-Part Mbira Music; 3) Interlocking in Three-Part Mbira Music; and 4) Interlocking in Multiple-Part Mbira Music. Three supporting categories are also presented: 1) Interlocking in Mbira "High-Line” Parts; 2) Interlocking in Accompanying Vocal Parts; and 3) Interlocking in Miscellaneous Accompanying Parts. Much of the data in this article was gathered by the author through his private instruction with the following distinguished Shona mbira players: Irene Chigamba, Tute Chigamba, Musekiwa Chingodza, Stella Chiweshe, Michael Kamunda, Forward Kwenda, Ephat Mujuru, and Luken Kwari Pasipamire.
\end{abstract}

Keywords: Kotekan, “event,” mbira dzavadzimu, kushaura, kutsinhira, hosho, and makwa.

Kotekan is a specific Balinese form of a more general category of musical interlocking-a phenomenon that occurs in several traditional music cultures of the world: for example, medieval France (vocal hocket), Java (gamelan imbal), the Andes (panpipe ensemble music), England (handbells), Congo (Pygmy singing), Sudan (Gumuz music), Tanzania (Gogo music), and Zimbabwe (Shona mbira music). Musical interlocking occurs in some forms of modern music as well: for example, Herbie Hancock's "Watermelon Man," drum and bugle corps drumline music (i.e., "splits"), and some forms of popular music (e.g., funk).

Interlocking in music may be defined as the rhythmic linear musical technique of usingthe alternation of various musical events so that one musical part alternately sounds while theothers rests. Normally two different musical parts, each performed by a different musician,are required for interlocking. How- ever, interlocking may also be produced by a singlemusician or by a group of several musicians.

In Bali two principle types of interlocking are predominant: interlocking betweentwo drums (kendang) and interlocking (kotekan) in gamelan music. In both types, theinterlocking effort is "composed," that is, designed to create a specific composite pattern. In Zimbabwe, however, interlocking patterns are often "improvised" and thus create unexpected composite patterns, both to the surprise and delight of the audience as well as to the performers themselves. In Bali interlocking patterns are rehearsed, while in Zimbabwe interlocking patterns are generally spontaneous and unrehearsed. In Balinese gamelan music, interlocking patterns are designed for an orchestral texture (i.e., doubled parts), while in Zimbabwean mbira dzavadzimu music, interlocking patterns are designed for a kammermusik ("chamber music") texture (i.e., one player per part). While in Balinese 
gamelan music, there may be eight or more musicians who execute two interlocking parts (polos and sangsih), in Zimbabwean mbira dzavadzimu music there are normally only two musicians who execute two interlocking parts (kushaura and kutsinhira).

Among the Shona people in Zimbabwe there exist five different types of mbira: karimba, njari, mbira dzavaNdau, matepe, and mbira dzavadzimu ((Berliner, 1978: 29-36). The karimba normally consists of 15 keys distributed over four manuals (i.e., two rows of keys [keyboards] plucked by the left hand and two rows for the right hand). The njari normally consists of 29 keys, also distributed over four manuals (two for the left hand and two for the right). The mbira nzavNdau consists of about 35 keys distributed over five manuals (three for the left hand and two for the right). The matepe consists of about 26 keys distributed over five manuals (three for the left hand and two for the right). The mbira dzavadzimu, which is the instrument under consideration in this study, consists of 22-25 or more keys distributed over three manuals (two for the left hand and one for the right). The right-hand manual, however, is treated as though it were two manuals (one three-key manual for the thumb and another with high pitches for the index finger). The mbira dzavadzimu (normally referred to simply as "mbira") is 1) the national instrument of Zimbabwe; 2) the only mbira type thought to have originated in Zimbabwe; 3) the most wide-spread mbira type in modern Zimbabwe; 4) themost wide-spread Zimbabwean mbira type outside of Zimbabwe (e.g., The United States, Europe, and Japan); 5) the most researched mbira type of Zimbabwe (e.g., Paul Berliner's The Soul of Mbira); and 6) the "mbira of the ancestors" (dza “of," vadzimu "ancestors").

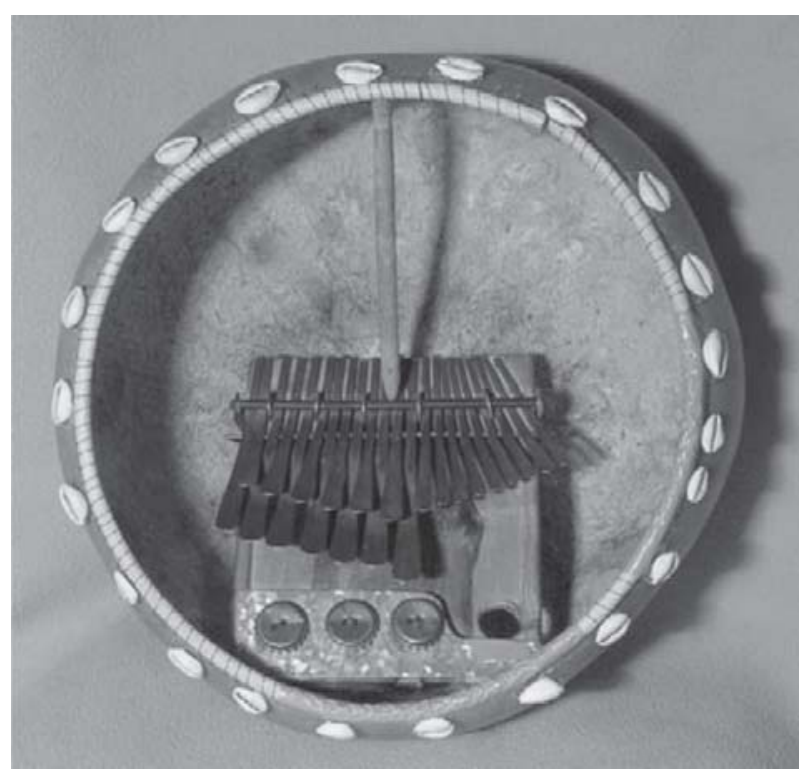

Picture 1. Shona mbira dzavadzimu

(Two left-hand manuals and one right-hand manual)

\section{Key layout}

$\mathrm{R}=$ Right-hand manual (RT = right-hand thumb; RI = right-hand index finger)

$\mathrm{L}=$ Left-hand upper manual

$\mathrm{B}=$ Left-hand lower (Bass) manual

Scale (Heptatonic)

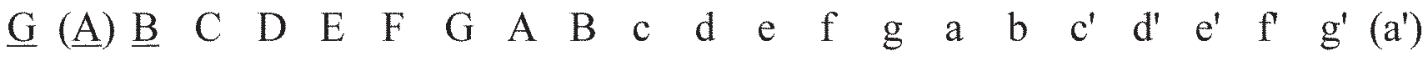

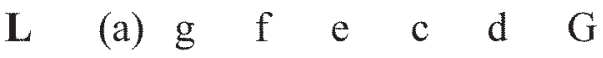
B

A $\quad F \quad$ E $\quad$ D $\quad$ C $\quad \underline{\text { B }} \underset{(A)}{\underline{G}}$

/ - RT - I

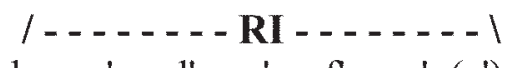

R $\quad$ B $\quad g \quad$ a

$g^{\prime}\left(a^{\prime}\right)$ 


\section{MBIRA NOTATION}

\section{Notational Symbols Used in This Study.}

For ease of cross reference with Paul Berliner's classic study The Soul of Mbira, most of the notational symbols used in this study are the same or similar to those used by Berliner. The horizontal line separates the right-hand (above the line) parts from the lefthand part (below).

$\begin{array}{ll}\mathrm{H} \wedge \ldots \ldots & \begin{array}{l}\text { Hosho rattles (^ represents the } \\ \text { main beat, - a pulse) }\end{array} \\ \mathrm{I} & \begin{array}{l}\text { Right-hand index finger (RI) } \\ \mathrm{T}\end{array} \\ \mathrm{L} & \text { Right-hand index finger (RT) } \\ \mathrm{B} & \text { Left-hand upper manual (L) }\end{array}$

On every pulse of an mbira piece, an mbira player will establish an "event": either a rest (by a silence) or a pitch (by plucking a key with a digit, a finger or a thumb). Both a rest and a pitch may occur on any pulse and on any manual. A pitch in the right hand is produced either by plucking upward with the index finger (I) or downward with the thumb (T), while a pitch in the left hand is produced with the thumb by plucking downward on either the upper manual (L) or downward on the bass manual (B). In addition, the index finger and thumb of the right hand may be plucked simultaneously, producing a two-pitch dyad. However, the upper manual and lower manuals of the left hand may only be plucked sequentially, since theleft thumb cannot play both manuals simultaneously. Structurally, traditional mbira piecesare generally constructed as a sequence of six-pulse groups as shown below.

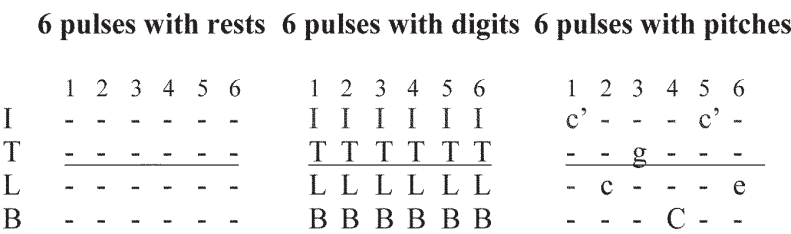

\section{A Complete Traditional Mbira Composition ("Nhemamusasa")}

The traditional piece "Nhemamusasa," is presented below in its entirety. The notation ofevery event, either a rest or a pitch is indicated. In performance its four twelve-pulse phrases (each indicated by underlining) are repeated over and over as a cycle of 48 pulses in length.

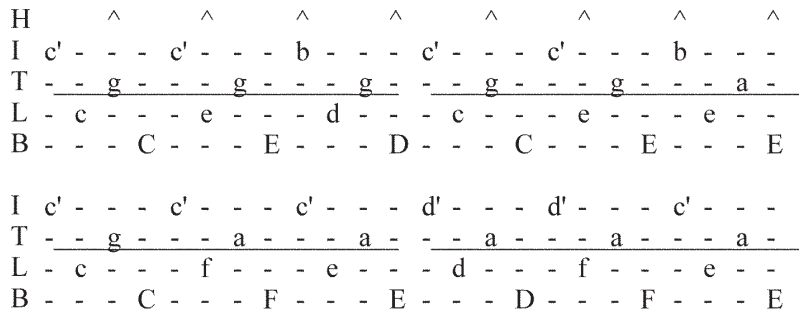

\section{INTERLOCKING IN SOLO MBIRA MUSIC}

\section{The Same Composition ("Nhemamusasa")}

For this study, an abbreviated notational system based upon the one above will be used. Thus, only pluckedkey events (pitches) will be indicated, while silent events (rests) will be represented by equally spaced empty pulses (see below). The alphabetical pitch names selected are consistent with those used in Berliner's The Soul of Mbira. What is presented in the notation immediately below is a traditional standard version of the so-called kushaura part ("leader" or "polos") of "Nhemamusasa." ((Berliner, 1978: 88111). (The interlocking kutsinhira ["follower" or "sangsih] part will be presented later.) A kushaura part represents the recognizable core of a composition (in this case "Nhemamusasa") and may be performed alone by a single mbira player. This particular kushaura represents a clear example of how interlocking may be produced by a single musician, for in the right-hand part the index finger (I) and the thumb $(\mathrm{T})$ parts interlock with each other, repeating a four-event, two-pitch I-T- pattern (i.e., I-T-IT-IT). Similarly, in the left-hand part the upper manual (L) and the bass manual (B) mirror the right-hand part and interlock with each other, in this case with a repeating four-event, two-pitch L-B- pattern (i.e, LB-L-B-L-B-). Additionally, the right-hand and lefthand parts interlock with each other, with a repeating four-pitch pattern ILTB (i.e., ILTB ILTB ILTB).

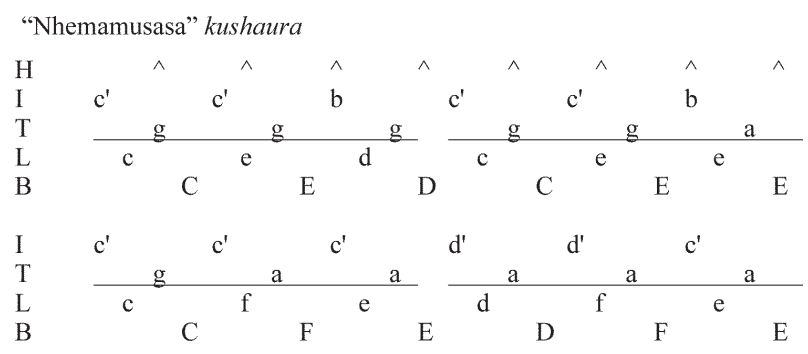


Similar to "Nhemamusasa," "Chakwi" is another example of how interlocking may be produced by a single musician. In this piece (As taught to the author by Stella Chiweshe (March 1998)), however, the index finger (I) and the thumb (T) of the righthand part interlock in a repeating three-event, twopitch IT- pattern (i.e., ITIT-IT-), while the upper manual (L) and the bass manual (B) of the left-hand part mirror the right-hard part by interlocking, in this case with a repeating three-event, two-pitch LBpattern (i.e., LB-LB-LB). "Chakwi” may also be rendered as a duet, by perfoming the kushaura as a strict canon to produce a following kutsinhira part.

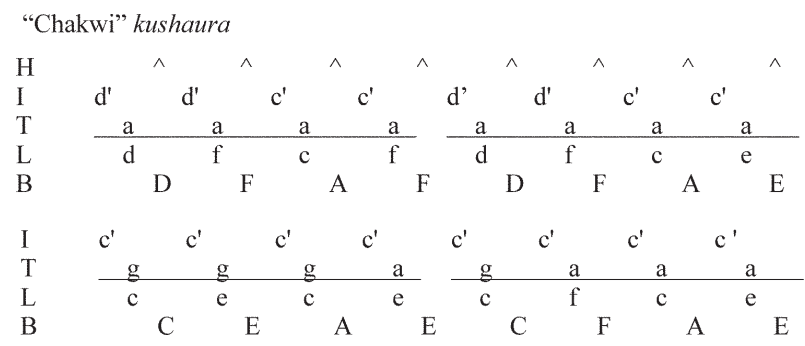

A third example of how interlocking may also be produced by a single musician is found in a well-known "Nhemamusasa Variation." In this piece (Masa, 2008: 17), the index finger (I) and the thumb (T) of the right-hand part interlock in a repeating four-event, three-pitch ITI- pattern (i.e., ITI-ITI-ITI-), while the upper manual (L) and the bass manual (B) of the left-hand part mirror the right-hard part by interlocking, in this case, with a repeating LBL- pattern (i.e., LBL-LBL-LBL-): except when the pitch " $A$ " (which is located in the bass manual) is required as a substitute for harmonic reasons. This "Nhemamusasa Variation" may also be rendered as a duet, by perfoming its kushaura with a suitable interlocking kutsinhira part.

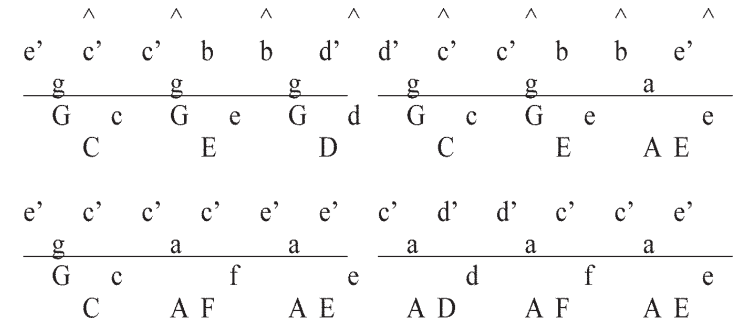

This "Nhemamusasa Variation," used as a kutsinhira, can be combined with the standard "Nhemamusasa" kushaura above to create an effective duet - a combination that adds density to the texture and that "sounds good" together (This is an expression used by Luken Pasipamire).

"Nhemamusasa Variation" (as a kutsinhira) combined with the standard "Nhemamusasa" kushaura. Duet version.

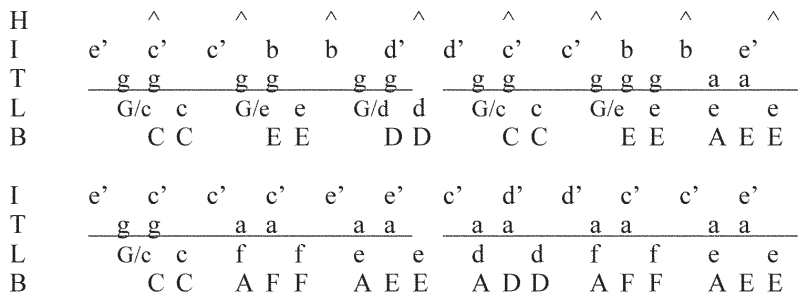

\section{INTERLOCKING IN TWO-PART MBIRA MUSIC}

As shown in the "duet" version of "Nhemamusasa Variation" directly above, when two mbira players perform together, an interlocking part (kutsinhira) is normally added to the leading kushaura part. Presented below is the traditional standard kutsinhira part that interlocks with the traditional standard kushaura of "Nhemamusasa" notated above. It, too, represents a clear example of how interlocking may also be produced by a single mbira player, for two different patterns are performed simultaneously: a repeating T-I-I- pattern in the right hand (i.e., T-I-IT-I-I-T-I-I-) against a repeating LB- pattern in the left hand (i.e., LB-LB-LB-). In Western music theory this would be viewed as polymeter: $3 / 4$ in the right hand and 6/8 in the left hand.

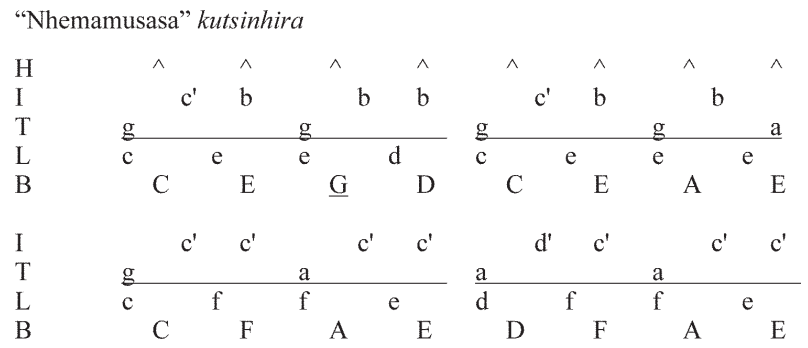


"Nhemamusasa" kushaura and kutsinhira combined

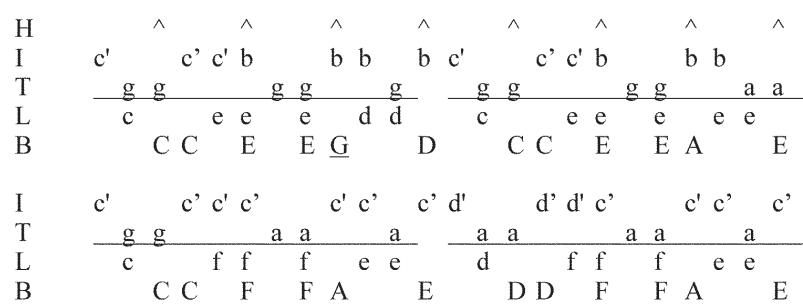

Just as the similar right-hand and left-hand parts of the kushaura of "Nhemamusasa" interlock with each other when performed by a single musician, two similar parts (i.e., a kushaura and its similar kutsinhira) interlock when performed by two different mbira players. As an example, the traditional standard version of the kushaura part of "Nyamaropa" (Berliner, 1978: 78-79) is presented below. Like the kutsinhira part to "Nhemamusasa," it consists of a repeating 3/4 pattern in the right hand set polymetrically against a repeating 6/8 pattern in the left hand. Many mbira pieces are related rhythmically to the kushaura/kutsinhira interlocking pattern of "Nyamaropa."

Kusharua/kutsinhira interlocking pattern of "Nyamaropa" and rhythmically related pieces. An " $x$ " represents a plucked pitch; "Rt" represents the right hand (either an I or a T); and "Lt" represents the left hand (either an L or a B).

$\begin{array}{ll}\mathrm{H} & \wedge \\ \mathrm{Rt} & \mathrm{x}-\mathrm{x}-\mathrm{x}-\text { kushaura } \\ \mathrm{Lt} & \mathrm{x} \times-\mathrm{x}- \\ \mathrm{Rt} & \mathrm{x}-\mathrm{x}-\mathrm{x}-\text { kutsinhira } \\ \mathrm{Lt} & \mathrm{x} \times-\mathrm{x}-\end{array}$

The interlocking kutsinhira part (below) to "Nyamaropa," similar to the kushaura part consists of a repeating 3/4 pattern in the right hand polymetrically against a repeating $6 / 8$ pattern in the left hand.

"Nyamaropa" kushaura

$\mathrm{H}$
$\mathrm{I}$
$\mathrm{T}$
$\mathrm{L}$
$\mathrm{B}$
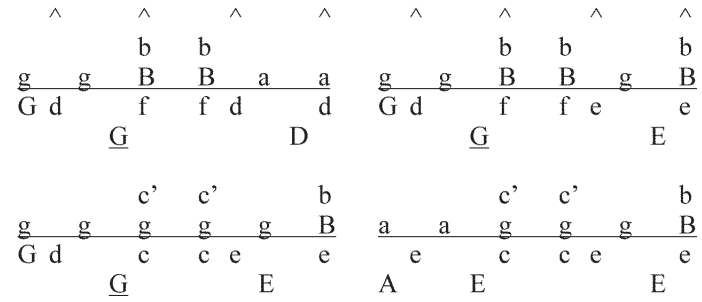

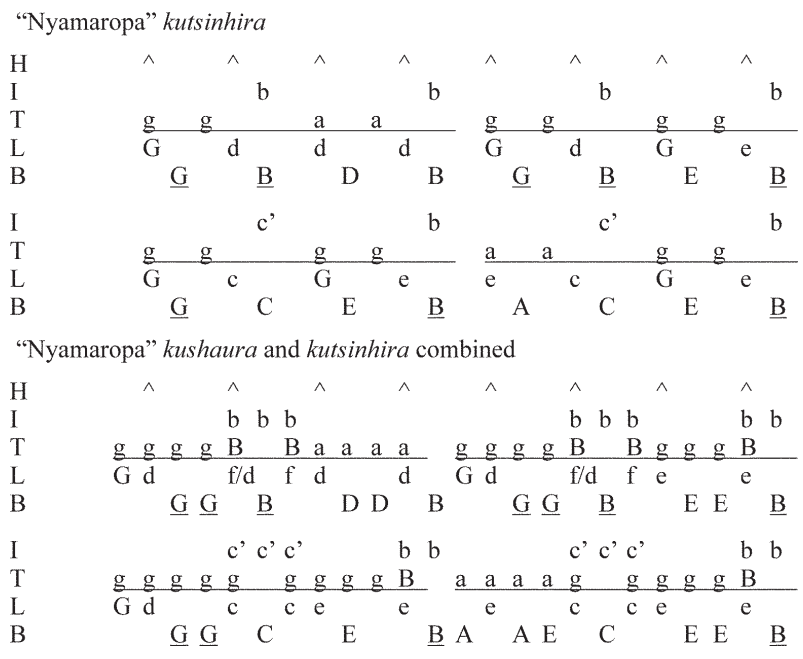

Another example of two similar parts (kushaura and its similar kutsinhira) that interlock when performed by two different mbira players is found in pieces related rhythmically to "Shumba." (As taught to the author by Luken Pasipamire (July 2004)). The interlocking kutsinhira part (below) to "Shumba," almost exactly the same as the kushaura part, consists of a repeating $3 / 4$ pattern in the right hand set polymetrically against a repeating $6 / 8$ pattern in the left hand: like "Nyamaropa," but with the right-hand part delayed by one pulse. The kushaura, kutsinhira, and combined parts to "Shumba" are presented on the following page. Many mbira pieces are related rhythmically to the kushaura/kutsinhira interlocking pattern of "Shumba."

Kusharua/kutsinhira interlocking pattern of "Shumba" and rhythmically related pieces. (The x's represent plucked pitches, Rt represents the right hand, Lt represents the left hand.)

$\mathrm{H}$

Rt $\quad \mathrm{x}-\mathrm{x}-\mathrm{x}-\quad$ kushaura

Lt $\quad x \quad x-x$ -

Rt

$\mathrm{x}-\mathrm{x}-\mathrm{x}-$ kutsinhira

Lt $\quad \mathrm{X} \quad \mathrm{X}-\mathrm{X}$ X 


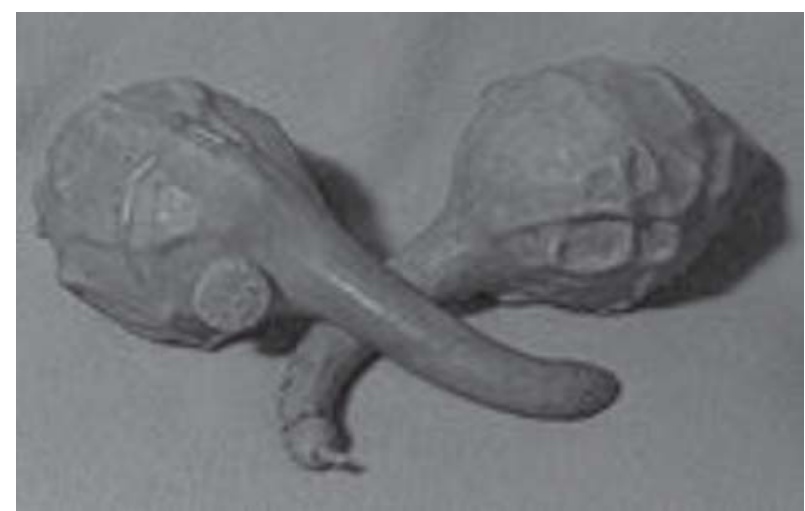

Picture 2. Shona hosho rattles

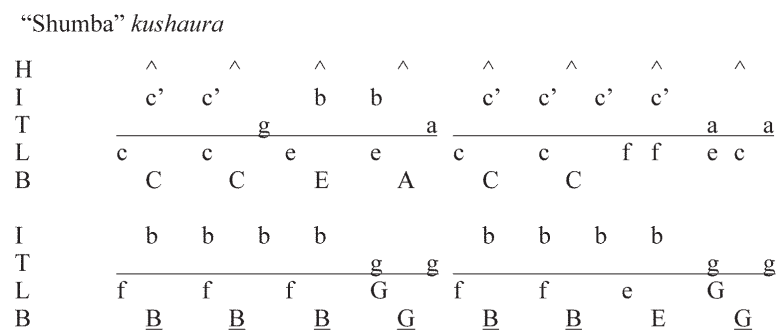

"Shumba" kutsinhira (similar to kushaura)

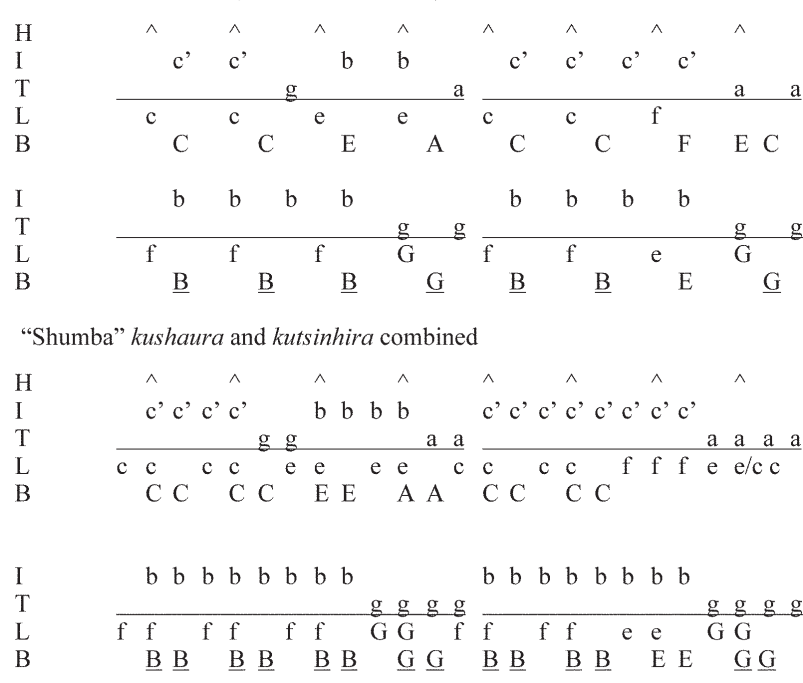

\section{INTERLOCKING IN THREE-PART MBIRA MUSIC}

Although it would be possible theoretically to construct an mbira piece as a strict threepart canon, normally third mbira parts, that interlock with kushaura/kutsinhira pairs, are countrapuntally independent of either one or both of the kushaura and kutsinhira parts. Three-part mbira playing appears to be widespread among the Shona in Zimbabwe: indeed, in some villages there exists specific terms for the third part (e.g., nhimura in Dambatsoko village) (Mujuru and Chris Gatsi, 2007: 23), while in others there are no such expressions for the practice, and the musicians perform interlocking third parts ad hoc by simply performing variations that add density to the texture and "sound good" together. The following is an example of a third part (nhimura) for the duet version of "Nhemamusasa," since it can be combined with both the kushaura and kutsinhira notated above.

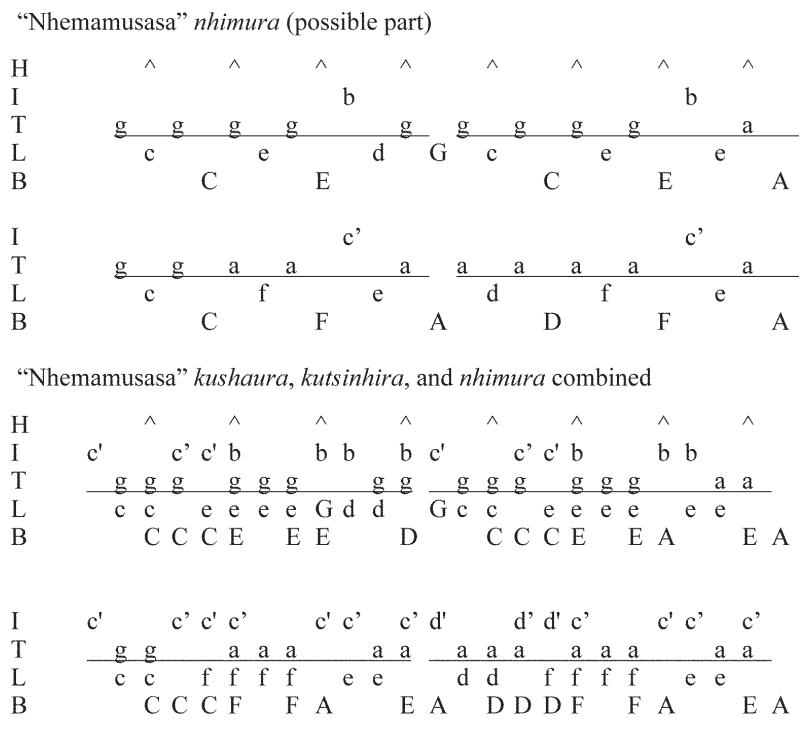

"Nyamaropa" provides another example of the effect of adding a third part (nhimura) to a traditional two-part piece. It can be combined with both the kushaura and kutsinhira parts notated above.

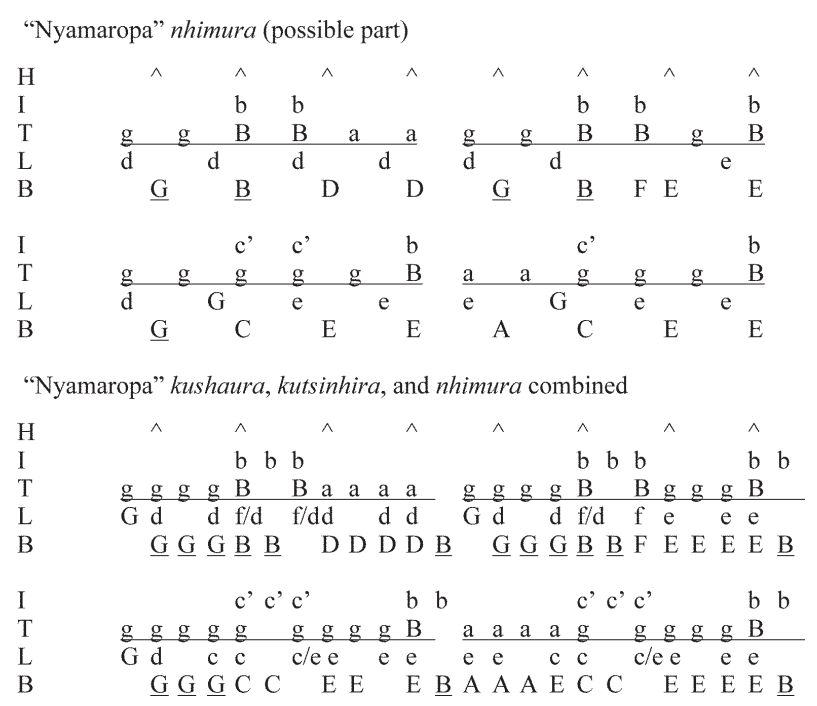


Yet another example of the effect of adding a third part (nhimura) to a traditiona twopart piece is given below with "Shumba." Its nhimura part can be combined with both the kushaura and kutsinhira parts that are notated above.

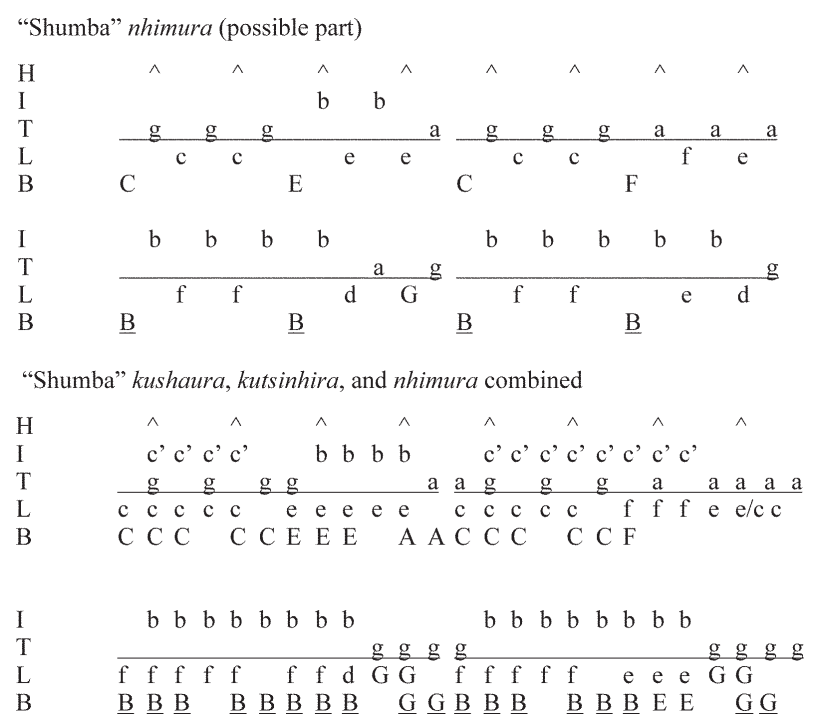

\section{INTERLOCKING IN MULTIPLE-PART MBIRA MUSIC}

For special occasions, such as the rain ceremony, relatively large groups (10-20 or more) of mbira players may perform simultaneously ((Berliner, 1978: 155157), either by doubling parts (i.e., several musicans rendering the kushaura part in unison, while others play the kutsinhira part in unison) or by playing multiple independent parts. The effect of doubling two (or three) parts by multiple performers creates an "orchestral” texture, while adding many different independent parts (nhimura) to the standard kushaura/kutsinhira pair creates a kammermusik ("chamber music") texture (i.e., one player per part). (Of course both textures, the "orchestral" and the "chamber," may be implemented simultanteously.)

The traditional piece "Taireva” provides an example of how three kushaura/kutsinhira pairs along with a nhimura part may be combined to create seven independent interlocking parts that add density to the texture and "sound good" together (see the following page).

\section{"Taireva" kushaura}

\section{$\mathrm{H}$ \\ I \\ $\mathrm{T}$ \\ L \\ B \\ I
T
L
B}
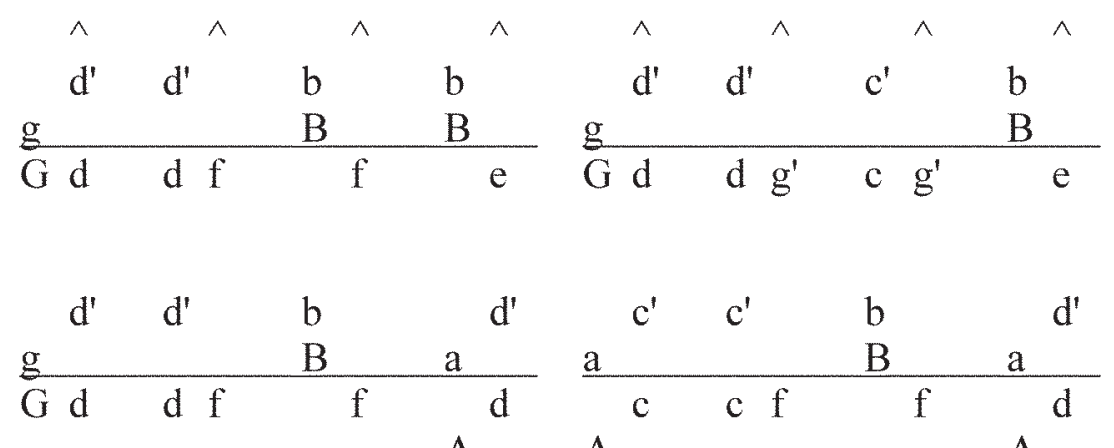

A

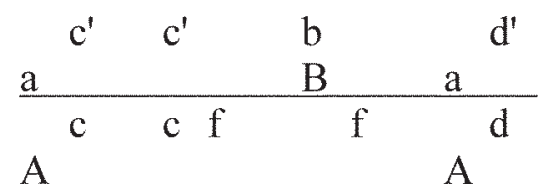

"Taireva" in seven independent interlocking parts $\left(1^{\text {st }} \& 2^{\text {nd }}\right.$ phrases only $)$

\begin{tabular}{|c|c|c|c|c|c|c|c|c|c|c|c|}
\hline $\mathrm{H}$ & $\wedge$ & $\wedge$ & & $\wedge$ & $\wedge$ & $\wedge$ & $\wedge$ & & & $\wedge$ & \multirow{4}{*}{ kushaura 1} \\
\hline $\mathrm{I}$ & $\mathrm{d}^{\prime}$ & $d^{\prime}$ & $\mathrm{b}$ & & $b$ & $\mathrm{~d}^{\prime}$ & $\mathrm{d}^{\prime}$ & $c^{\prime}$ & & 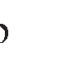 & \\
\hline $\mathrm{T}$ & $\mathrm{g}$ & & $\mathrm{B}$ & & B & $\mathrm{g}$ & & & & 3 & \\
\hline $\begin{array}{l}\mathrm{L} \\
\mathrm{B}\end{array}$ & $\mathrm{G} \mathrm{d}$ & $\mathrm{d} \mathrm{f}$ & & $f$ & $\mathrm{e}$ & $\mathrm{G} \mathrm{d}$ & $\mathrm{d} \mathrm{g}^{\prime}$ & $\mathrm{c}$ & & $\mathrm{e}$ & \\
\hline $\mathrm{I}$ & & b & $\mathrm{b}$ & $\mathrm{b}$ & b & & $c^{\prime}$ & $c^{\prime}$ & $c^{\prime}$ & $b$ & \multirow{4}{*}{ kutsinhira 1} \\
\hline $\mathrm{T}$ & g & & & & & $g$ & & & & & \\
\hline $\mathrm{L}$ & $\mathrm{G}$ & $\mathrm{G} / \mathrm{d}$ & $\mathrm{f}$ & & $\mathrm{e}$ & $\mathrm{G}$ & $G$ & $\mathrm{c}$ & & & \\
\hline B & $\underline{\mathrm{G}}$ & $\underline{B}$ & & $\underline{B}$ & $\mathrm{E}$ & $\underline{\mathrm{G}}$ & C & & & $\mathrm{E}$ & \\
\hline
\end{tabular}




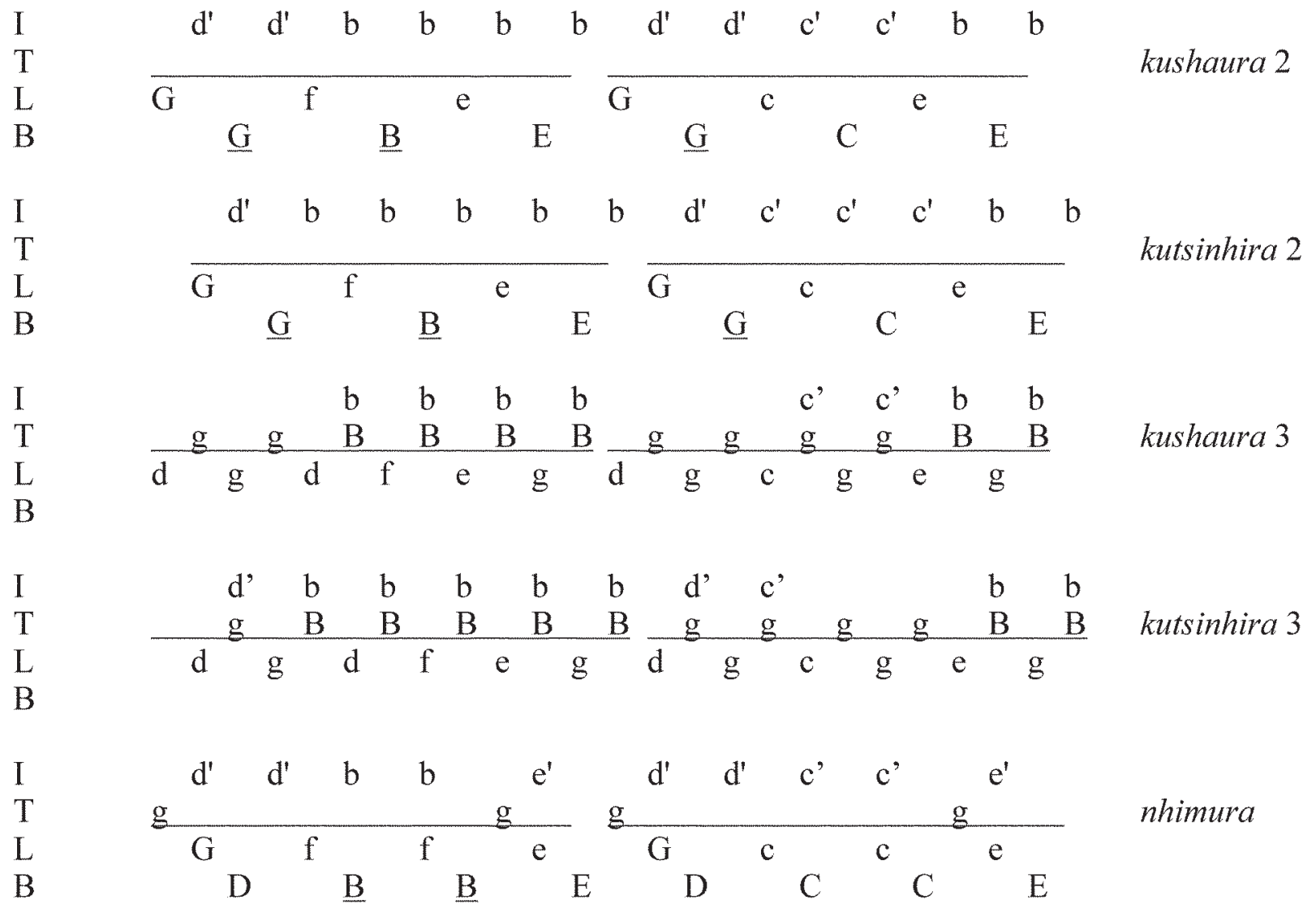

"Taireva" with seven independent interlocking parts combined

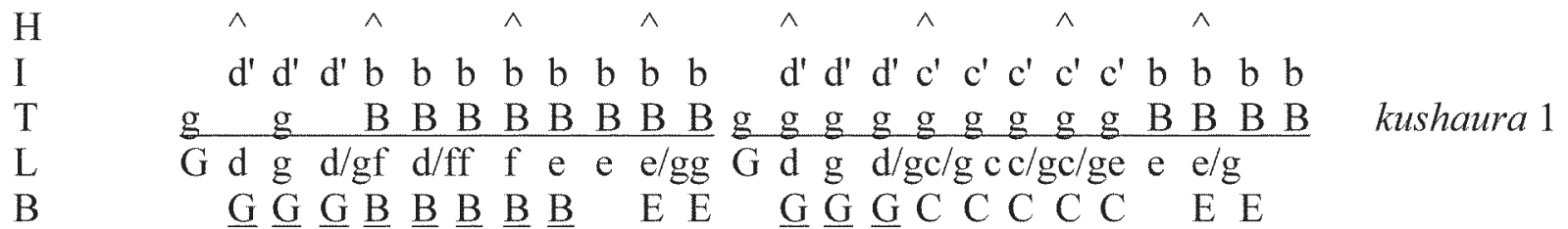




\section{INTERLOCKING IN MBIRA \\ “HIGH-LINE” PARTS}

A special type of interlocking (nhetete) (This is an expression used by Luken Pasipamire and others) in two-part mbira music is the interplay of the high sounding keys on the mbira-interlocking between the index fingers of a kushaura and kutsinhira pair.
During a particularly exciting moment of a performance of mbira music, someone present (a musican, a dancer, an auditor) will often shout out "nhetete, nhetete," meaning "play the 'thin' keys" (i.e., the high right-hand pitches). The resulting descending repeated melodies produces a distinctive effect, like descending "raindrops from the sky." (This is an expression used by Luken Pasipamire).

"Nhemamusasa" kushaura $\left(1^{\text {st }} \& 2^{\text {nd }}\right.$ phrases only)

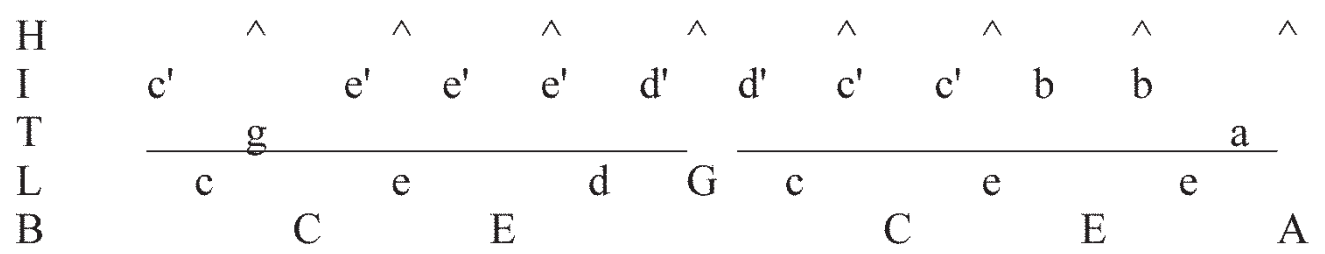

"Nhemamusasa" kutsinhira $\left(1^{\text {st }} \& 2^{\text {nd }}\right.$ phrases only $)$

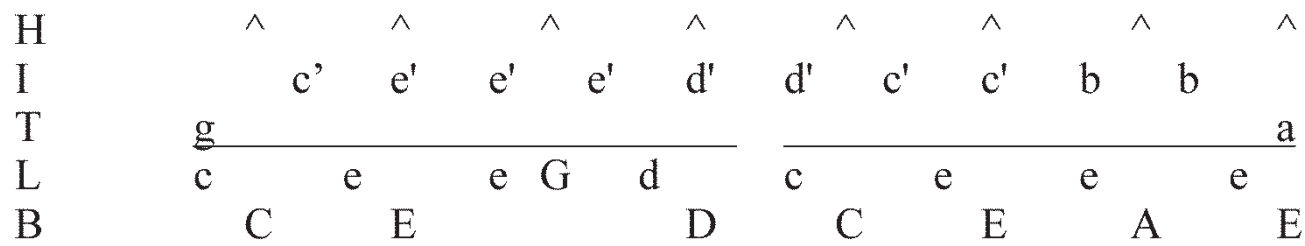

"Nhemamusasa" kushaura and kutsinhira high lines combined $\left(1^{\text {st }} \& 2^{\text {nd }}\right.$ phrases only $)$

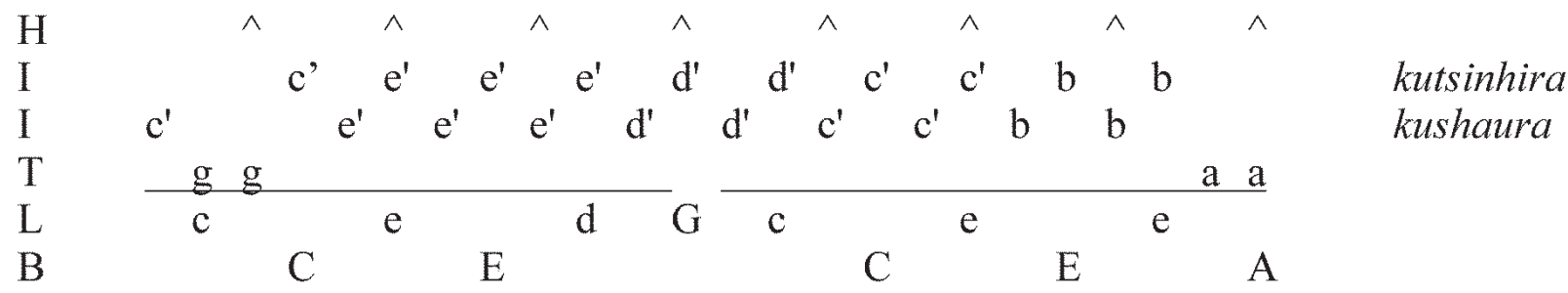

To further illustrate the practice of nhetete, another pair of interlocking descending highline parts for "Nhemamusasa" is provided below. In this example, the lines are even higher than those in the previous example.

"Nhemamusasa" kushaura and kutsinhira high lines combined $\left(1^{\text {st }} \& 2^{\text {nd }}\right.$ phrases only $)$

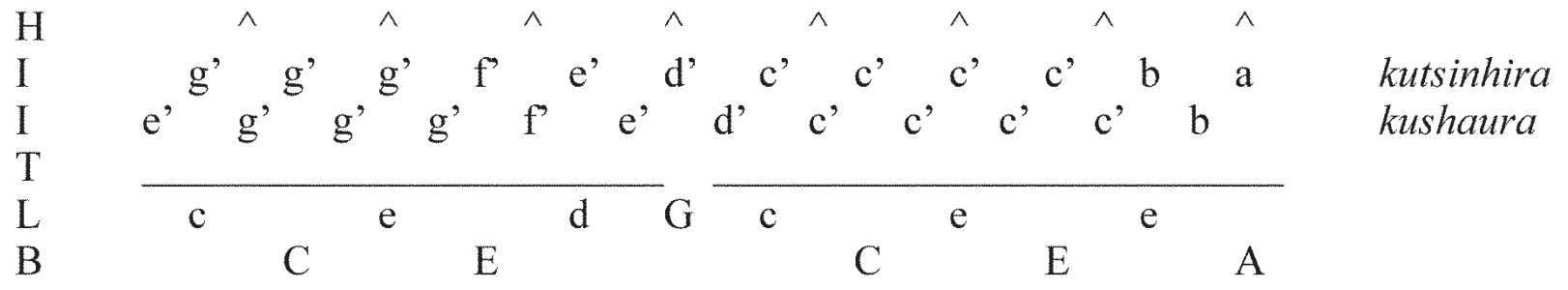




\section{INTERLOCKING IN ACCOMPANYING VOCAL PARTS}

In addition to the various forms of mbira interlocking indicated above (solo, two parts, three parts, and multiple parts), accompanying interlocking vocal parts are commonly sung along with mbira pieces (Berliner, 1978: 160-185). In sung realizations of "inherent rhythms" embedded in the mbira parts, the different vocal parts interlock with each other by beginning at different starting points in the repeating cycle of a piece. Within its range of three octaves, the mbira can generate inherent rhythms throughout its full range, thus creating parts for children, women, and men-parts that we can label, for convenience in this study, as “soprano," "alto," "tenor,” and "bass.” The score of the first and second phrases of the standard kushaura mbira part of "Nhemamusasa" (in bold) provided, along with seven vocal melodies, directly below demonstrates how seven different vocal parts 1) are realizations of melodies embedded in the mbira parts (shown by the vertical alignment of pitches); 2) are sung in different vocal ranges ("soprano," "alto," "tenor," and "bass); and 3) interlock by beginning at different starting points. Although long narrative song texts (kudeketere) may be sung, most of the vocal parts (e.g., those presented in the score below) consist of short repeating patterns (mahon'era and huro) that are sung to vocables (i.e., various syllables without meaning) (Berliner, 1978: 114-121).

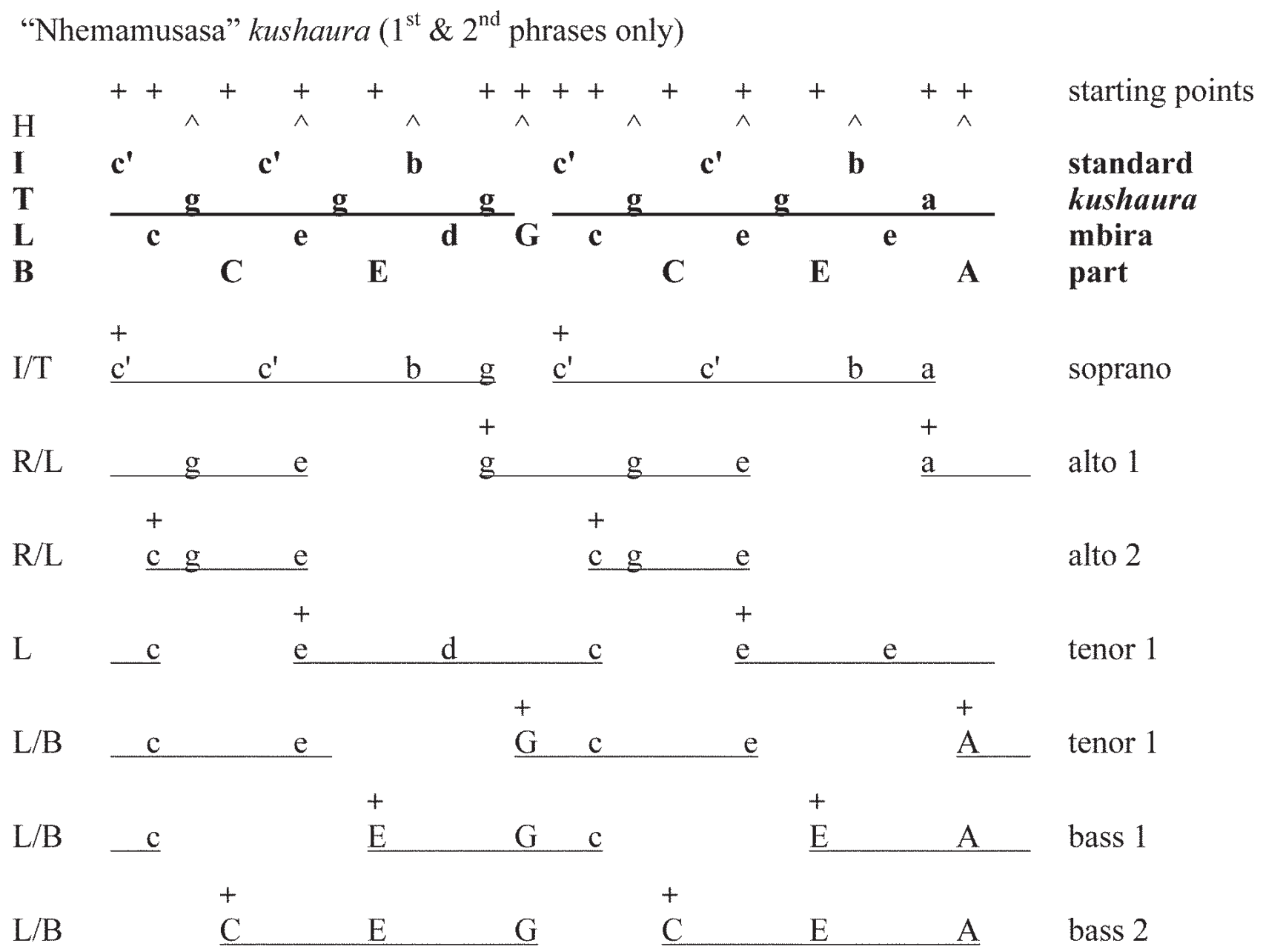




\section{INTERLOCKING IN MISCELLANEOUS ACCOMPANYING PARTS}

Finally, during a complete performance of mbira music in the context of a Shona ceremony in Zimbabwe, other miscellaneous interlocking parts typically accompany the mbira and vocal parts. These "parts" consist of 1) interlocking hand clapping (makwa) (Berliner: 1978: 114-115); 2) interlocking foot-stomping percussive sounds from the dancers (normally the men); 3) whistling sounds that interlock with the general musical texture or that imitate the vocal parts; 4) interlocking humming that imitates the bass vocal parts; and 5) interlocking "noise" associated with socializing (e.g., shouting, talking, whispering, etc.) (As observed in July 2004 by the author in Mondoro, Zimbabwe).

\section{REFERENCES}

Berliner, Paul F. (1978), The Soul of Mbira: Music and Traditions of the Shona People of Zimbabwe, University of California Press, Berkeley.

Bohlman, Philip V. (1992), Excursions in World Music, Prentice Hall.

Hayashi, Erika. (2008), Luken Kwari Pasipamire Song Book, Japan.

Kaemmer, John. (1975), "The Dynamics of a Changing Music System in Rural Rhodesia." Ph.D. dissertation, Indiana University.

Kauffman, Robert. (1970), "Multi-Part Relationships in the Shona Music of Rhodesia." Ph.D. dissertation, University of California at Los Angeles. Kauffman, Robert. (1969), "Some Aspects of Aesthetics in the Shona Music of Rhodesia." Ethnomusicology 13, no. 3 (September 1969).
Kubik, Gerhard. (1964), "Generic Names for the Mbira.” African Music Society Journal 3, no. 3 (1964).

Kubik, Gerhard. (1965), "Generic Names for the Mbira." African Music Society Journal 3, no. 4 (1965).

Kubik, Gerhard. (1962), “The Phenomenon of Inherent Rhythms in East and Central African Instrumental Music.” African Music Society Journal 3, no. 1 (1962).

Masa (compiler). (2008), Traditional Mbira Scores of Luken Pasipamire. Japan.

Mujuru, Fradreck and Chris Gatsi. (2007), Mbira Score Book, Japan.

Stone, Ruth M. (ed.) (1998), The Garland Encyclopedia of World Music Vol. 1: Africa, Garland Publications, Inc, New York.

Tracey, Hugh. (1969), “The Mbira Class of African Instruments in Rhodsia (1932)," African Music 4 (3) 1969.

Tracey, Andrew. (1974), "The Famly of the Mbira." Zambezia 3, no. 2 (1974).

Tracey, Andrew. (1970), How to Play the Mbira (DzaVadzimu), The International Library of African Music, Roodepoort, South Africa.

Tracey, Hugh. (1969), "The Mbira Class of African Instruments in Rhodesia (1932).” African Music Society Journal 4, no. 3 (1969).

William, Barry Michael. (2001), Learning Mbira: A Beginning, PA: HoneyRock, Everett. 